\title{
EL ESTADO ISLÁMICO, EL SALAFISMO Y LA SECURITIZACIÓN DE LA RELIGIÓN ${ }^{1}$
}

Guillermo Ospina Morales ${ }^{(a)}$

THE ISLAMIC STATE, SALAFISM AND THE SECURITIZATION OF RELIGION

O ESTADO ISLÂMICO, O SALAFISMO E A SECURITIZAÇÃO DA RELIGIÃO

Fecha de recepción: 30 de septiembre del 2019

Fecha de aprobación: 15 de mayo del 2020

Disponible en línea: 29 de mayo del 2020

\section{Sugerencia de citación:}

Ospina Morales, G. (2020). El Estado Islámico, el salafismo y la securitización de la religión. Razón Crítica, 9, 131158. doi: $10.21789 / 25007807.1610$

(1)

Artículo de reflexión. Se desarrolla a partir de algunas de las conclusiones de la tesis de maestría en Estudios Políticos e Internacionales titulada El Estado Islámico y la seguridad societal: sectarismo y violencia intercomunitaria en Irak y Siria.

(a) Guillermo Ospina Morales

Magíster en Estudios Políticos e Internacionales, Universidad del Rosario, Colombia guillermo.ospinam@gmail.com

http://orcid.org/0000-0001-6159-5667 


\section{R E S U M E N}

La securitización, como enfoque teórico, permite comprender las dinámicas que se producen cuando un asunto se considera un tema de seguridad. No obstante, cuando la religión se aborda como objeto referente, produce una dinámica tanto ofensiva como defensiva para responder a la amenaza. En este sentido, se analiza cómo el Estado Islámico realiza un proceso de securitización de la religión que se fundamenta en principios teológicos, y bajo el cual enmarca sus objetivos, legitima sus acciones, define al enemigo y controla a la población. De esta manera, se acude al concepto de "ramas de la securitización" para comprender las diferentes audiencias a las que dirige su discurso salafista.

PALABRAS CLAVE: Securitización, religión, seguridad, salafismo, Estado Islámico. 


\section{A B S T R A C T}

Securitization, as a theoretical approach, allows understanding the dynamic forces around an issue that is considered a security matter. However, when religion is approached from this perspective, it leads both to an offensive and a defensive dynamic to answer to a given threat. In this sense, this work studies how the Islamic State (IS) carries out a process of securitization of religion based on theological principles that are used for establishing its objectives, legitimizing its actions, targeting the enemy, and controlling the population. In this way, the concept of "branches of securitization" is used in order to understand the different audiences to which IS Salafist discourse is directed.

\section{KEYWORDS: Securitization, religion, security, Salafism, Islamic State.}

\section{R E S U M O}

A securitização, como abordagem teórica, permite compreender as dinâmicas produzidas quando um assunto é considerado um tema de segurança. Contudo, quando a religião é abordada como objeto referente, produz uma dinâmica tanto ofensiva quanto defensiva para responder à ameaça. Nesse sentido, é analisado como o Estado Islâmico realiza um processo de securitização da religião fundamentado em princípios teológicos e a partir do qual delimita seus objetivos, legitima suas ações, define o inimigo e controla a população. Dessa maneira, recorre-se ao conceito de "ramos da securitização" para compreender os diferentes interlocutores aos quais o discurso salafista é dirigido.

PALAVRAS-CHAVE: securitização, religião, segurança, salafismo, Estado Islâmico. 


\section{N T R O D U C C I Ó N}

Las últimas décadas del siglo XX, en particular las de 1980 y 1990, atestiguaron el crecimiento de las reivindicaciones identitarias. Durante este periodo, la etnia, la lengua y la religión ocuparon un lugar importante en la explicación de la violencia y de los conflictos que se presentaron en el mundo. Los conceptos tradicionales de las Relaciones Internacionales se mostraban insuficientes para comprender esta realidad, por lo que se desarrollaron nuevas posturas para entender las guerras y los conflictos.

El concepto de seguridad se enfrentó a nuevos debates, dando lugar a un proceso de "ampliación” y "profundización” (Buzan y Hansen, 2010; Saleh, 2010). De este modo, gracias al trabajo de la Escuela de Copenhague ${ }^{1}$ de estudios sobre seguridad, aparecieron nuevas concepciones teóricas como los sectores de la seguridad ${ }^{2}$, la seguridad societal y la securitización, que desafiaron la concepción realista de la seguridad, caracterizada por su enfoque estadocéntrico y militarista.

La Escuela de Copenhague se enmarca en la concepción constructivista de la seguridad, por lo que se interesa en comprender la naturaleza y el proceso mediante el cual se construyen las amenazas, en contraposición a los paradigmas tradicionales que las consideraban objetivas. En este sentido, la securitización busca explicar por qué

\footnotetext{
1 Término acuñado por Bill McSweeney para referirse a los miembros del Copenhagen Peace Research Institute como Barry Buzan, Ole Waever, Jaap de Wilde, Lene Hansen, entre otros (McSweeney, 1996).

2 La Escuela de Copenhague identifica cinco sectores de la seguridad: militar, político, económico, societal y ambiental; cada uno de estos tendría una dinámica de seguridad particular según el tipo de amenazas que se presenten (Buzan, et al., 1998).
} 
ciertos temas son abordados como un asunto de seguridad y las posibles respuestas ante ellos. Sin embargo, este concepto ha sido utilizado principalmente para analizar sistemas democráticos en los que se acude a “políticas especiales” para legitimar ciertas acciones que, de otra manera, no se permitirían para enfrentar una amenaza.

Dentro de las dinámicas de seguridad contemporáneas, la religión tiene un papel fundamental, producto de la amenaza que han representado los grupos islamistas radicales que han surgido a partir de la década de 1980. Estos grupos se enmarcan dentro de la doctrina salafista ${ }^{3}$, que considera que es necesario retornar a la práctica prístina del islam como una forma de regresar a una época dorada en la se profesaban y seguían fielmente los preceptos divinos revelados a Mahoma y en la que la sociedad musulmana no se encontraba en decadencia y subyugada ante Occidente.

El salafismo también considera que este "retorno al pasado" es la forma adecuada para defender la religión, modificar el orden internacional actual y "purificar" moralmente a las sociedades musulmanas. Sin embargo, es importante señalar que existen diversos grupos salafistas que, si bien comparten una serie de preceptos y principios teológicos, difieren respecto al método (manhaj) que consideran adecuado para alcanzar sus objetivos.

De este modo, existen distinciones entre los grupos salafistas, que pueden clasificarse en quietistas, políticos y yihadistas (Wagemakers, 2017 $)^{4}$. Los primeros representan aquellos que se concentran en la prédica, la educación y el activismo social; los políticos, que se involucran en partidos, participan en las elecciones locales y el activismo social mediante organizaciones; por último, los yihadistas, quienes toman un postura militante que busca aplicar la ley sagrada estrictamente, derrocar los gobiernos apóstatas que existen en Medio Oriente y expulsar a Occidente de la tierras del islam mediante un llamado a la yihad ${ }^{5}$ (Wagemakers, 2017, p. 15-19).

\footnotetext{
3 El salafismo proviene del término árabe al-salaf alsalih (los píos predecesores), que se utiliza para referirse a las tres primeras generaciones de musulmanes.

4 Una de las clasificaciones más importantes de los grupos salafistas es la realizada por Quintan Wiktorowicz (2006), que establece tres tipos: puristas, políticos y yihadistas.

5 Wagemakers $(2017$, p. 18) señala que existen tres tipos de yihad armada: clásica, que refiere a la defensa de las tierras del islam frente a las amenazas externas; revolucionaria, que es resultado del rechazo a los gobiernos del mundo musulmán por su negativa a aplicar la ley sagrada; global, que busca disuadir a los países occidentales, y en particular a Estados Unidos, que apoyan a los gobiernos apostatas y dictatoriales que existen en Medio Oriente.
} 
Sin embargo, esta clasificación no es estricta. Diversos autores coinciden en señalar que existen varios tipos de salafismo que se sobreponen y que están sujetos a las acciones, los métodos, los objetivos, las relaciones con los regímenes políticos y los contextos locales en los que se desarrollan (Ayoob, 2004; Izquierdo Brichs, 2013; Martin y Barzegar, 2010). Las posturas más ultraconservadoras, literalistas y violentas son minoritarias ${ }^{6}$.

Lo anterior no implica desconocer y minimizar los actos violentos que cometen los grupos salafistas-yihadistas, y que tienen un impacto en la seguridad internacional, estatal y societal. Por ejemplo, el asesinato del presidente egipcio Anwar al-Sadat por miembros de la Yihad Islámica en 1981 -considerado la primera aparición del terrorismo islamista (Veiga, 2009)-, los atentados al World Trade Center en 2001 o el asesinato de miles de soldados iraquíes en Camp Speicher en 2014.

En la actualidad, se considera al Estado Islámico como el grupo salafista-yihadista más importante y una de las principales amenazas globales. Las barbáricas y atroces acciones que ha cometido, como ejecuciones, decapitaciones, crucifixiones, violaciones, atentados suicidas, entre muchas otras, han sido transmitidas a través de la propaganda del grupo a múltiples audiencias, permitiéndole crecer como organización y avanzar en sus objetivos.

El uso del discurso salafista-yihadista por parte del Estado Islámico le ha permitido desarrollar un proceso de securitización de la religión que se fundamenta en postulados teológicos y es utilizado para justificar sus acciones, dado que el islam se encuentra en peligro existencial, en el marco de una lucha -con matices apocalípticos-que se libra entre el bien y el mal (Ospina Morales, 2019).

De esta manera, el presente artículo tiene por objetivo explorar cómo el Estado Islámico transmite y adapta su discurso salafista-yihadista -como actor securitizador- y su relación con las diversas audiencias a las que se dirige a través de la propaganda y las declaraciones que realiza. Así, en primer lugar, se analizan los elementos que conforman la teoría de la securitización y algunas concepciones alternativas que permiten

\footnotetext{
6 Gran parte de los grupos salafistas que surgieron en la década de 1980 han experimentado una transformación de sus agendas y objetivos. De este modo, la relación con los regímenes políticos, tanto dictatoriales como democráticos, han mutado del total rechazo hacia la participación y la negociación; también se expresa una mayor disposición por adquirir espacios sociales y de poder dentro de los sistemas políticos establecidos y el abandono de la idea del establecimiento de un Estado islámico (Izquierdo Brichs, 2013).
} 
estudiar el caso de los grupos salafistas-yihadistas; en segundo lugar, se estudian las particularidades que implica comprender la religión a partir de la securitización; y, por último, se busca comprender los elementos del discurso securitizador que desarrolla el Estado Islámico y que transmite a múltiples audiencias con el fin de ganar adeptos y simpatizantes, legitimar sus acciones, definir y disuadir al enemigo y alcanzar múltiples audiencias. Para ello, se abordan diversas publicaciones del Estado Islámico, como discursos, declaraciones, revistas y videos ${ }^{7}$.

\section{LA SEGURITIZACIÓN, EL ACTO DISCURSIVO Y LA CONSTRUCGIÓN DE LAS AMENAZAS}

La securitización desafió la concepción realista de la naturaleza objetiva de las amenazas. Propuso un enfoque constructivista que busca comprender cómo, a partir de un acto discursivo, un asunto se convierte en un tema de seguridad, a través del espectro entre lo no-politizado, lo politizado y lo securitizado (Buzan et al., 1998).

En este proceso se pueden identificar varios elementos constitutivos: a) un objeto referente; b) un acto discursivo; c) el actor securitizador; d) una audiencia; y e) unas condiciones facilitadoras. Algunos de estos han tenido mayor atención dentro de la propuesta de la Escuela de Copenhague, por lo que analizarlos y abordar algunas de las críticas que se han realizado permite comprender de mejor manera el desarrollo conceptual que ha tenido en el último tiempo.

\section{a) El objeto referente}

Es el término con el cual se designa aquello cuya existencia se encuentra en peligro, y que por ser considerado valioso debe ser protegido y requiere de unas medidas extraordinarias para lograrlo de forma efectiva.

b) El acto discursivo

La securitización hace del acto discursivo el centro de su análisis, ya que considera que el pronunciamiento de un tema como un asunto de seguridad, constituye la seguridad en sí (Buzan, 2007, p. 36). Esta

7 La mayoría de las fuentes consultadas se encuentran en inglés, dadas las limitaciones idiomáticas que existen. 
dependencia en el acto discursivo es una de las críticas más fuertes a la securitización, debido a que se contrapone a la intersubjetividad que sustenta la propuesta de la Escuela de Copenhague. Además, considera al lenguaje como el único medio por el cual es trasmitido un significado, dejando de lado aspectos como las imágenes, los silencios, las prácticas burocráticas o las acciones, como señalan las críticas de la Escuela de París (Balzacq et al., 2015; McDonald, 2008).

c) El actor securitizador

Hace referencia al individuo, o al grupo, que a través de un acto discursivo presenta un asunto como un problema de seguridad (Buzan et $a l ., 1998$, p. 40). Aunque la Escuela de Copenhague reconoce que puede ser problemático identificar a los actores securitizadores, comúnmente son señalados los líderes políticos, los burócratas, el gobierno y los grupos de presión (Buzan et al., 1998, p. 40). Por tal razón, algunos autores afirman que la teoría de la securitización es estrecha, dado que se concentra en determinados actores, esencialmente, en líderes políticos y élites (McDonald, 2008) y deja de lado a los actores sin poder, ya sean voces marginales o no estatales. Por lo anterior, es necesario ampliar el espectro en la identificación de los posibles actores para comprender otros procesos de securitización que tienen lugar fuera de las élites políticas y estatales, como ocurre en el caso de la religión y los grupos salafistas-yihadistas.

d) La audiencia y las medidas extraordinarias

El éxito del proceso de securitización radica en la aceptación del acto discursivo por parte de una audiencia determinada, otorgando legitimidad a un actor con el fin de hacer uso de unas medidas extraordinarias para la defensa del objeto referente. Para la Escuela de Copenhague, la seguridad es construida a partir de esta interacción. Sin embargo, no existe un criterio determinado para definir lo que constituye una audiencia suficiente para aprobar un proceso de securitización ni las condiciones bajo las cuales ocurre la aceptación (Balzacq et al., 2015; Vuori, 2008).

Aunque normalmente se asume que la audiencia es el público en general o los habitantes de algún Estado, el análisis de Juha Vuori (2008) afirma que pueden existir audiencias determinadas que brindan legitimidad por sus características especiales, como es el caso de los países no democráticos, donde también existe la necesidad de justificar unas medidas extraordinarias frente a las élites en el poder o grupos fundamentalistas que apoyan al régimen. De esta manera, la audiencia 
a ser convencida de las acciones de seguridad cambia según el sistema político, las intenciones del actor y, en general, al contexto en el cual la securitización se lleva a cabo (Vuori, 2008).

e) El contexto y las condiciones facilitadoras

El éxito o fracaso del proceso de securitización también depende de las condiciones bajo las cuales ocurre, estas son: 1) la gramática de seguridad, 2) el capital social del enunciador, 3) las relacionadas a la amenaza y 4) las referentes a la audiencia (Balzac, 2005, citado en Vuori, 2008, p. 70). Estas pueden agruparse en internas y externas, las primeras corresponden a las características performativas del discurso, es decir, que cumplen los requisitos y los procedimientos gramaticales y lingüísticos necesarios para su aceptación; mientras que las segundas están asociadas al contexto histórico y a la compresión de seguridad que exista (Balzacq et al., 2015, pp. 13-14; Buzan, et al., 1998, p. 32).

Por otro lado, el contexto, en su aspecto interno, debe considerar el "momento" en que ocurre la securitización, es decir, el instante en que algo se convierte en un asunto de seguridad. Esto ha sido centro de debate, pues no se ha determinado si la securitización subyace en la enunciación por parte de un actor o, por el contrario, en la aceptación de la audiencia (McDonald, 2008).

Finalmente, la securitización usualmente ha sido utilizada en sistemas democráticos, por lo que su análisis en otros contextos permite reconocer la importancia de la audiencia a la cual está dirigido el mensaje, así como las razones, justificaciones o argumentos que exigen según las intenciones del actor (Vuori, 2008). De esta manera, el éxito de un proceso de securitización está relacionado con la audiencia a la que es dirigido, la construcción gramático-lingüística exigida y el contexto histórico en el cual se presenta el discurso. Sin embargo, los resultados pueden variar, a pesar de que ocurran en condiciones similares (Balzacq et al., 2015; Vuori, 2008).

Como se observa, la securitización se ha concentrado en el acto discursivo y en los actores políticos estatales, por lo que los elementos restantes de la teoría se encuentran limitados y la intersubjetividad que pretende es cuestionada. No obstante, definir la audiencia y el momento en que es aceptado el discurso y ocurre la securitización enfrenta bastantes dificultades. Es por esta razón que es importante considerar aquellas propuestas que estudian el papel de la audiencia en la construcción del acto discursivo y las razones por las que el actor securitiza un tema. 
En este sentido, Judith Butler (1997, citada en McDonald, 2008) señala que el acto discursivo puede ser ilocutivo o perlocutivo; el primero hace referencia a la construcción de la realidad a través de la enunciación por parte del hablante, mientras el segundo destaca la intención que se busca generar en la audiencia. Por lo anterior, la securitización puede ser utilizada para diferentes propósitos dependiendo de la intención que se tenga al realizar el acto discursivo. De esta manera, Vuori (2008), con base en John Searle (1979) y Daniel Vanderveken (2002), señala que pueden existir cinco tipos distintos de actos discursivos: $\operatorname{asertivos}^{8}$, directivos ${ }^{9}$, $\operatorname{comisivos}^{10}$, expresivos ${ }^{11}$ y declarativos ${ }^{12}$.

Esta taxonomía permite que la securitización sea analizada como un acto discursivo complejo, compuesto por una serie de discursos más básicos y simples que, teniendo en cuenta la fuerza ilocutiva y el efecto que se busque sobre la audiencia, permite identificar cinco "ramas de la securitización" (Vuori, 2008): 1) para elevar un asunto en la agenda; 2) para justificar actos futuros; 3) para disuadir; 4) para legitimar actos pasados o para reproducir el estatus de seguridad de un asunto, y 5) para controlar.

Por lo anterior, la securitización no es un proceso uniforme y homogéneo que resulte únicamente de la capacidad performativa del actor securitizador, sino que también es un proceso que se adapta de acuerdo con las audiencias a las que se dirige el acto discursivo y a las intenciones que se posean al realizarlo. Este enfoque brinda importantes herramientas analíticas para comprender la dinámica de seguridad que originan los grupos salafistas, como el Estado Islámico, que buscan securitizar la religión.

\section{LA RELIGIÓN COMO DINÁMICA DE SEGURIDAD}

Desde inicios de la década de 1980 hasta nuestros días, diferentes grupos salafistas-yihadistas han surgido en diferentes partes del mundo, en particular en Medio Oriente y el norte de África, afectando tanto a los Estados como a la población civil. Sin embargo, a pesar de que las acciones que estos grupos

8 El hablante presenta una afirmación que señala un estado de cosas en el mundo real.

9 El orador intenta que el oyente realice alguna acción, la cual es señalada en el pronunciamiento.

10 El discurso implica el compromiso de actuar o hacer algo por parte del hablante.

11 El contenido proposicional expresa los sentimientos o actitudes del orador sobre algún estado de cosas.

12 Las proposiciones del hablante provocan/buscan provocar cambios en el mundo real. 
perpetran se presenten como actos irracionales y de brutal violencia, tienen sentido dentro de un proceso de securitización de la religión.

Como señalan Laustsen y Waever (2003), abordar la religión en la agenda de seguridad implica analizarla como "religión en sí"; es decir, comprenderla como un objeto susceptible de ser amenazado y que por lo tanto posee una dinámica de seguridad particular. De este modo, proponen a la fe como un posible objeto referente para desarrollar un nuevo sector de la seguridad, que aborde fenómenos como el activismo religioso y el fundamentalismo.

Laustsen y Waever (2003) señalan que la amenaza a la práctica de la fe pone en riesgo la existencia de la identidad como Ser. En este sentido, el Ser es considerado un tipo de identidad fundamental (Laustsen y Waever, 2003, p. 158), resultante del vínculo con lo divino a través de los objetos sagrados, los cuales deben ser protegidos. Esta concepción de la religión parte de los postulados de Kierkegaard y Bataille, quienes señalan a la fe como el elemento central del discurso religioso ${ }^{13}$ y como resultado de la distinción entre lo sagrado y lo profano. De este modo, para asegurar la fe deben protegerse las representaciones de lo divino, que se codifica en objetos, personas, lugares y prácticas que son sacralizadas. Estos son considerados espíritus manifestados de forma material, cuya pérdida significa romper el contacto con lo divino. Así, la securitización de la fe y, por consiguiente, de la religión implica defender los objetos sagrados de cualquier amenaza (Laustsen y Waever, 2003, p. 159).

De esta manera, la relación entre el discurso religioso y la securitización lleva a la aparición de los conflictos cuando: a) un grupo religioso es considerado una amenaza a la sobrevivencia del Estado; b) se percibe que la fe está amenazada por un actor o un proceso no religioso (modernización, tecnología, industrialismo, etc.); c) existe otro discurso religioso o actor que amenaza a la fe, por ejemplo, la Reforma protestante. Así, la religión pierde su carácter trascendente, rompe la división entre "el cielo y la tierra", y gracias a la securitización se convierte en ideología (Laustsen y Waever, 2003, p. 165). Esta última entendida como un sistema de ideas, más o menos coherentes, que tienen el carácter de fantasías, canalizan deseos y ofrecen formas de movilizar una audiencia y, por tanto, permiten legitimar una determinada política. De este modo, la religión

13 El discurso religioso se destaca por defender la fe verdadera, la alabanza al dios correcto y de la forma correcta, en vez de una identidad o una comunidad (Laustsen y Waever, 2003, pp. 151-152). 
funciona como un significante que permite a un actor ser más exitoso en un movimiento securitizador y como justificación moral y política a las acciones de grupos armados.

Sin embargo, esta forma de entender la religión parte de una definición performativa, que se muestra limitada y unidimensional para comprender la violencia y los conflictos religiosos (Sheikh, 2014b). Está influenciada por la compresión occidental y cristiana de la fe, en la cual el hombre se encuentra alejado de lo trascendente bajo la imagen del pecado, por lo que Laustsen y Waever concluyen que la negación de esta división corresponde a una fe securitizada a través del discurso de actor. Esto conlleva a que el análisis sea estrecho, ya que desconoce el hecho de que varias culturas y sociedades no hacen una distinción entre lo sagrado y lo profano (Sheikh, 2014b, p. 258).

Además, Sheikh (2014b) señala que la definición de Laustsen y Waever es estrecha por ser esencialista, y porque desconocen que los discursos religiosos no buscan únicamente defender la fe, pues también pueden ser lugares santos (tierras o templos) o la ley sagrada. Por lo anterior, propone dos posibles opciones analíticas para el abordaje de la religión: en primer lugar, considerarla como un concepto multidimensional que puede referir a prácticas y rituales, la narrativa o mítica, la doctrina, las emociones y las experiencias, la ética y la ley, lo social y lo institucional, o lo material (Smart, 1996, citado en Sheikh, 2014b). De este modo, se establecen potenciales objetos referentes, algunos de ellos más sencillos que otros de securitizar, pero que pueden ser utilizados por los grupos fundamentalistas según los fines que posean y la audiencia a la que se dirijan.

En segundo lugar, Sheikh señala que es posible demarcar el sector religioso al considerar a la doctrina ${ }^{14}$ como el objeto referente, no solamente porque las doctrinas permiten analizar conjuntamente la fe, la política y la identidad, sino que además las disputas doctrinales -tanto religiosas como seculares- son centrales en muchos conflictos actuales (Sheikh, 2014a; 2014b). Además, las doctrinas poseen similitud con la religión, ya que el mantenimiento de creyentes o seguidores es necesario para garantizar su existencia, por lo que son estos quienes aprueban las medidas necesarias cuando las doctrinas son securitizadas.

14 La doctrina es definida como principios particulares, valores o ideas acerca de la forma de vivir, que son aceptados como verdaderos por un grupo de personas, y sostenidos por mitos legendarios que hacen que sea valioso morir por esta (Sheikh, 2014a). 
En este sentido, según Sheikh (2014b), la doctrina como objeto referente ofrece tres aportes para la comprensión de los conflictos: primero, permite entender cómo los grupos fundamentalistas securitizan alguna de las dimensiones de la religión con el fin de llevar su mensaje a varias audiencias, justificar sus acciones y ganar seguidores; segundo, la defensa del objeto referente es trasformada en un discurso ofensivo que se origina en la justificación religiosa-doctrinal; tercero, la complejidad de la securitización en el sector religioso, dada la naturaleza de los posibles objetos referentes y de las doctrinas, puede permitir que la dinámica de seguridad sea multisectorial y genere procesos de macrosecuritización. De esta manera, es posible señalar que grupos como el Estado Islámico realizan un proceso de securitización y cómo este genera una dinámica de seguridad que repercute en la seguridad de los Estados y comunidades.

La tabla 1 presenta una síntesis de las propuestas de Laustsen y Waever (2003) y Sheikh (2014b) frente al proceso de securitización de la religión.

Tabla 1. Securitización y religión

\begin{tabular}{cc}
\hline PROCESO DE \\
SECURITIZACIÓN & SECTOR RELIGIOSO/DOCTRINAL \\
\hline Objeto referente & Fe/Doctrina \\
\hline Acto discursivo & $\begin{array}{c}\text { Amenaza existencial al Ser y los objetos } \\
\text { sagrados que impiden la práctica de la fe } \\
\text { Amenaza existencial a principios, valores e } \\
\text { ideas acerca de la forma de vivir }\end{array}$ \\
\hline Actor securitizador & Líderes religiosos \\
Líderes políticos \\
Miembros de la religión \\
Cualquier individuo
\end{tabular}

Fuente: elaboración propia a partir de Laustsen y Waever (2003) y Sheikh (2014b). 


\title{
EL ESTADO ISLÁMICO Y LA SECURITIZACIÓN DE LA RELIGIÓN
}

\author{
El 29 de junio de 2014, Abu Muhammad al-Adnani, por entonces vocero \\ del Estado Islámico, proclamó la reinstauración del califato en Irak y Siria. \\ De este modo, su discurso anunciaba el cumplimiento de "la promesa \\ de Alá"15 que cambiaría la situación de la comunidad musulmana, \\ establecería la ley sagrada y defendería la verdadera religión.
}

Hoy las naciones de los kurf (infieles) en Occidente están aterrorizadas. Hoy las banderas de Shaytān (Satán) y sus partidarios han fallado. Hoy la bandera del tawhid (monoteísmo) se levanta con su gente. Hoy los musulmanes son honrados. Ahora el khilāfah (califato) ha regresado, golpeando los cuellos del enemigo. Ahora el khilāfah ha regresado a pesar de sus oponentes. Ahora el khilāfah ha regresado; le pedimos a Alá (el Exaltado) que siga la metodología profética. Ahora la esperanza se está actualizando. Ahora el sueño se ha hecho realidad. (al-Adnani, 2014; traducción propia)

La proclamación también representaba la transición entre la estatalidad y el califato. Una nueva etapa de la organización, que cambió su nombre de Estado Islámico de Irak y Siria (reconocido por su sigla en inglés, ISIS) por Estado Islámico ${ }^{16}$. Aunque el anuncio fue controversial ${ }^{17}$,

15 Título del discurso pronunciado por al-Adnani.

16 Desde su creación en 2003, el Estado Islámico ha tenido diferentes denominaciones que reflejan los cambios en el liderazgo y en los objetivos propuestos. De este modo, durante su etapa dentro de la insurgencia contra la ocupación norteamericana en 2003, liderada por Abu Musab AlZarqawi, se conoció como Jama'at al-Tawhid wal-Jihad. Entre 2004 y 2011, estableció una alianza con Al-Qaeda y fue reconocida por ser la rama iraquí de la organización, Tanzim Qaidat al-Jihad fi Bilad al-Rafidayn (Al-Qaeda en la tierra entre dos ríos). Tras la muerte de al-Zarqawi, cambió su nombre a Estado Islámico de Irak (ISI, por su sigla en inglés), liderado por Abu Omar al-Baghdadi y Abu Hamza al-Muhajir entre 2011-2013. La muerte de ambos líderes, producto del ataque de tropas norteamericanas, dejó la organización bajo el mando de Abu Bark al-Baghdadi. Desde entonces, la organización tuvo una serie de importantes conquistas territoriales que derivaron en su cambio de nombre: se conoció, entre 2013 y 2014, como Estado Islámico de Irak y el Levante (ISIL, en inglés) y Estado Islámico de Irak y Siria/al-Sham (al-Dalwa al-Islamiya fi Irak wa al-Sham).

17 Tras la proclamación del califato, los foros de simpatizantes yihadistas y los diferentes grupos fundamentalistas fueron partícipes del debate acerca de su legitimidad. Así, se presentó una disputa teológica entre el Estado Islámico y Al-Qaeda. La metodología de esperar, ganar el apoyo de la población e implementar la Sharia como pasos previos a la proclamación de un califato, distaba de la acelerada y violenta manera como Abu Bark al-Baghdadi lo había alcanzado. No obstante, cabe señalar las diferencias ya existentes frente a la violencia desmedida de al-Zarqawi y su grupo hacia la población chiita, lo cual ya había generado diferencias entre Bin Laden y al-Zarqawi. Incluso, reconocidos miembros de Al-Qaeda como Adam Gadahm y Abu Muhammad al-Maqdisi expresaron su rechazo a la violencia de Al-Qaeda en Irak. (Gartenstein-Ross et al., 2015; McCants, 2015; Stern y Berger, 2015; Weiss y Hassan, 2015). 
la posterior aparición del líder Abu Bark al-Baghdadi, en la mezquita de Mosul el 4 de julio de 2014, hizo real algo que, de otra forma, sería alcanzado únicamente a través de la espera, la paciencia y la confianza en la voluntad de Alá.

El Estado Islámico, como grupo salafista-yihadista, comparte varios preceptos teológicos como la realización de la yihad ${ }^{18}$, takfir ${ }^{19}$, al-wala' wa albara $^{20}$, yahiliyyah ${ }^{21}$, hakkimiyyah ${ }^{22}$ y tawhid ${ }^{23}$ que se han desarrollado a través del tiempo (Maher, 2017; Ospina Morales, 2019). Sin embargo, difiere con otros grupos frente a la metodología (manhaj) que eligen para llevarlos a cabo (Wagemakers, 2017, p. 14). En este sentido, es importante señalar la visión apocalíptica y escatológica que posee el Estado Islámico, que señala la necesidad de defender la "verdadera" religión en medio de la guerra que se libra entre el bien y el mal, propia del fin de los tiempos (McCants, 2015). De esta manera, establece la amenaza que se cierne sobre el islam, como señaló al-Baghdadi en su discurso.

Los musulmanes fueron derrotados después del fin del khilāfah (califato). Su Estado dejó de existir, por lo que los incrédulos pudieron debilitar y humillar a los musulmanes, dominarlos en todas las regiones, saquear sus riquezas y recursos y despojarlos de sus derechos. Lo lograron atacando y ocupando sus tierras, colocando a sus agentes traicioneros en el poder para gobernar a los musulmanes con un puño de hierro y difundiendo consignas deslumbrantes y engañosas como: civilización, paz, coexistencia, libertad, democracia, secularismo, baazismo, nacionalismo y patriotismo, entre otros eslóganes falsos.

Esos gobernantes continúan esforzándose por esclavizar a los musulmanes, alejándolos de su religión con esas consignas. Entonces,

18 Aunque es un término que posee diferentes interpretaciones, lingüística y literalmente significa lucha o esfuerzo (cfr. Esposito, 2003).

19 Es el pronunciamiento o la práctica de excomunión que realiza un musulmán sobre otro al señalarlo como infiel y no islámico. Este término deriva de la palabra kafir, que significa infieles o "aquel que se niega a aceptar la revelación divina" (cfr. Esposito, 2003).

20 Lealtad a Alá y repudio o disociación de los infieles (cfr. Esposito, 2003).

21 Traduce ignorancia. Este término designa las creencias de la época pre-islámica (cfr. Esposito, 2003).

22 El gobierno de Alá. Asegurar la soberanía divina mediante la aplicación de la ley sagrada (cfr. Esposito, 2003).

23 Hace referencia a la unicidad de Alá. Es expresada de tres formas: el reconocimiento de la omnipotencia de Dios (tawhid al-rububiyya); la unicidad de la divinidad de Dios, que implica la adoración únicamente de Él (tawhid al-uluhiyya); y la unicidad de los nombres y atributos de Dios (tawhid al-asma wa'l-sifat), a través de la aceptación literal de los nombres y atributos de Alá (Meijer, 2010, p. 39). Esta división es atribuida al pensador medieval Ibn Taymiyyah. 
el musulmán se aleja de su religión, no cree en Alá y se somete vergonzosamente a las leyes shirk (politeístas) hechas por el hombre del este y el oeste, viviendo despreciablemente y humillantemente como seguidor, repitiendo esas consignas sin voluntad ni honor, o viviendo perseguido, atacado y expulsado, para terminar siendo asesinado, encarcelado o terriblemente torturado, por la acusación de terrorismo. Porque el terrorismo es no creer en esas consignas y creer en Alá. Terrorismo es referirse a la ley de Alá para juzgar. Terrorismo es adorar a Alá como Él te ordenó. Terrorismo es rechazar la humillación, la subyugación y la subordinación. Terrorismo es el musulmán que vive como musulmán, honorablemente, con poder y libertad. El terrorismo es insistir en sus derechos y no renunciar a ellos. (al-Baghdadi, 2014, julio 1 traducción propia)

Kfir (2015) señala que el Estado Islámico se presentaba como proveedor de seguridad y estabilidad en medio de los conflictos en Irak y Siria. Así, el mensaje salafista logra una mayor receptividad dentro de la población, gracias al ofrecimiento de bienes y servicios tangibles e intangibles, lo que le permitió ganar adeptos locales y simpatizantes a nivel mundial.

El discurso securitizador del Estado Islámico se centra en la defensa de la unicidad de Alá (tawhid) y es complementado con otros principios teológicos que definen el comportamiento de los individuos -del "buen musulmán”- y señalan la importancia de demostrar la lealtad a Dios, rechazar a los infieles y actuar de manera correcta según la ley sagrada (Ospina Morales, 2019). De esta manera, Sheikh (2014b, p. 268) señala que la descripción de la amenaza por parte del actor securitizador debe enmarcarse en la imaginería religiosa para tener éxito y ofrecer evidencia que apele a emociones, aspectos espirituales o referencias a interpretaciones éticas y legales de la religión.

En este sentido, es importante recordar la propuesta de Vuori (2008) de las "ramas de la securitización”, que establece diferentes tipos de securitización según las intenciones del actor y los efectos que desea provocar en la audiencia. Dada la amplia variedad de la propaganda del Estado Islámico, las múltiples audiencias a las que se dirige su mensaje y la naturaleza religiosa de su discurso, esta propuesta permite comprender varios aspectos del proceso de securitización que realiza.

Como señala Sheikh (2014b), una de las características fundamentales de la securitización de la religión es que desarrolla un discurso que es 
simultáneamente defensivo y ofensivo. De este modo, el Estado Islámico a través de sus narrativas presenta, de manera simultánea, el diagnóstico y la respuesta a la situación de la comunidad sunnita en Irak y Siria. Su discurso securitizador (religioso) identifica como la principal amenaza al complot que existe en Medio Oriente entre chiitas y Occidente; esta constituirá la fase defensiva en la que se identifica al enemigo. Mientras que la fase ofensiva insiste en la necesidad de actuar en contra de los infieles y los apóstatas para enfrentar la situación de emergencia en que se encuentran los sunnitas, por lo que los actos violentos, los ataques, los atentados y las masacres se hallan justificadas para enfrentar la amenaza, pero también para disuadir al enemigo. De este modo, la tabla 2 muestra la relación entre las "ramas de la securitización” y la dinámica defensiva/ ofensiva del discurso del Estado Islámico.

Tabla 2. El discurso religioso y las "ramas de la securitización"

\begin{tabular}{|c|c|c|}
\hline $\begin{array}{l}\text { DISCURSO } \\
\text { RELIGIOSO }\end{array}$ & $\begin{array}{l}\text { RAMAS DE LA } \\
\text { SECURITIZACIÓN }\end{array}$ & NARRATIVA \\
\hline Defensivo & $\begin{array}{c}\text { Elevar un asunto en la } \\
\text { agenda }\end{array}$ & $\begin{array}{c}\text { Existe una guerra (sectaria) } \\
\text { declarada por los chiitas en contra } \\
\text { de los sunnitas y el islam, quienes } \\
\text { actuando en complicidad con } \\
\text { Occidente, se han adueñado del } \\
\text { poder con el fin de eliminar a los } \\
\text { "buenos musulmanes". }\end{array}$ \\
\hline Ofensivo & $\begin{array}{l}\text { Legitimar actos } \\
\text { futuros. } \\
\text { Disuasión del } \\
\text { enemigo. } \\
\text { Justificar actos } \\
\text { pasados. }\end{array}$ & $\begin{array}{l}\text { Es necesario eliminar al chiismo } \\
\text { de Irak, se debe atacar al enemigo } \\
\text { sin consideración alguna, bien } \\
\text { sea en los cuarteles, las oficinas } \\
\text { gubernamentales, mercados o } \\
\text { zonas residenciales. Así mismo, } \\
\text { todas aquellas representaciones de } \\
\text { apostasía, idolatría e infidelidad. }\end{array}$ \\
\hline
\end{tabular}

Fuente: elaboración propia.

Esto se observa de forma explícita en las declaraciones de Abu Musab al-Zarqawi, considerado el padre fundador del Estado Islámico, entre 20042005. Por ejemplo, en su carta a Osama Bin Laden señala sobre los chiitas

Estos [han sido] una secta de traición y engaño a lo largo de la historia y a lo largo de los siglos. Es un credo que tiene como objetivo combatir 
a los sunnitas. Cuando cayó el repulsivo régimen Ba'ath, el lema de los chiítas era "venganza, venganza, de Tikrit a Al Anbar". Esto muestra el alcance de su rencor oculto hacia los sunnitas. Sin embargo, sus ulemas y políticos han podido controlar los asuntos de su secta, para que la batalla entre ellos y los sunnitas no se convierta en una guerra sectaria abierta, porque saben que no tendrán éxito de esta manera. Saben que, si se produjera una guerra sectaria, muchos en la nación [islámica] se levantarían para defender a los sunnitas en Irak. Como su religión es de disimulación, procedieron maliciosa y astutamente de otra manera. Comenzaron tomando el control de las instituciones del Estado y sus ramas de seguridad, militares y económicas. (al-Zarqawi, 2004, párr. 11; traducción propia)

Frente al uso del lenguaje, es importante destacar cómo el Estado Islámico se refiere a los chiitas ${ }^{24}$. La palabra rafida (el que rechaza) ha sido la forma más común de llamarlos. Sin embargo, el uso del término safávidas aumentó desde que Abu Bark al-Baghdadi asumió el liderazgo del grupo. Estos términos revelan dos aspectos de la identificación como enemigo de la población chiita: el primero es religioso, y lo señala como un pueblo que rechaza a los califas y a Alá; mientras que el segundo es étnico, al equiparar al chiismo con Irán. De este modo, los elementos étnicos y religiosos son utilizados para movilizar a la población sunnita y fomentar el sectarismo (Saeed, 2015).

La intervención iraní dentro de los conflictos de Irak y Siria permitió que el Estado Islámico, y otros grupos salafistas, explotaran las divisiones sectarias y presentaran la situación de la población sunnita como un ataque contra su religión orquestado desde Irán. En el caso de Siria, la batalla de Al Quseir (Homs), entre finales de 2012 y mediados de 2013, demostró el apoyo de Hezbolá y de militares iraníes al régimen de Bashar al-Assad. A partir de entonces, la retórica de los grupos rebeldes, los grupos salafistas y los foros yihadistas en internet explotaron la narrativa sectaria y la utilizaron como herramienta de reclutamiento entre la población sunnita a lo largo de Medio Oriente, al invitarlos a defender a sus hermanos y hermanas en Siria de la amenaza chiita (Lister, 2015, p. 91).

24 En el caso sirio, los alauitas, que son una rama del islam chiita, son denominados por los grupos radicales como "nusayri", en referencia al fundador de esta rama del islam, Ibn Nusayr. Este término es considerado negativo por los alauitas, ya que indica que sus creencias fueron creadas por un hombre y no provienen de Dios (cfr. Landis, 2013). 
Las acciones del gobierno de al-Assad y de los grupos paramilitares que le apoyaban reforzaron esta narrativa. Las masacres que se presentaron en Baniyas y al-Bayda, en la provincia mayoritariamente alauita de Tartus, en mayo de 2013, se caracterizaron por la selección de las víctimas según su filiación política y religiosa (Human Rights Watch, 2013; Lister, 2015, p. 131). Esto facilitó que tanto los clérigos como los grupos armados salafistas-yihadistas realizaran un llamado a la comunidad sunnita en Medio Oriente, como audiencia, a responder a la yihad en Siria.

Esta instrumentalización de la lucha sectaria es mucho más evidente en el caso iraquí. La radicalización de las protestas que se presentaron durante 2013 fue un terreno fértil para que el Estado Islámico (para entonces denominado ISI) fomentara la desconfianza de los sunnitas hacia el gobierno. Así se expresaba el vocero de la organización, Abu Mohammad al-Adnani

Este supuesto proceso político es un sucio pretexto de los magi rafida para realizar sus complots safawi (pertenecientes a la lucha de rafida contra los sunnitas) para debilitar a los sunnitas y llevarlos a ser una minoría oprimida que podría ser fácilmente controlada, reprimida y humillada. ¡Oh Dios! Que mi gente pueda saber; que mi pueblo pueda ver; ¡que mi gente pueda escuchar! (2011, pp. 11-12; traducción propia)

De este modo, como se observa en la tabla 3, la propaganda que produjo el Estado Islámico entre 2011-2013, tuvo como objetivo capitalizar la victimización de la comunidad sunnita y la exclusión del poder durante el gobierno de Nouri al-Maliki.

Esta lectura sectaria de los conflictos de Irak y Siria permitía que las acciones del Estado Islámico se presentaran como legítimas y como una forma de retaliación y disuasión del enemigo, pero también como el cumplimiento de los preceptos religiosos. Por ejemplo, las campañas militares Breaking the Walls ${ }^{25}$ y The Soldier's Harvest era presentadas

25 Esta campaña -que abarcó de julio de 2012 a julio de 2013-consistió en una serie de ataques con coches bomba (VBIED, por sus siglas en inglés) a lo largo de Irak. Durante este periodo, ocho prisiones fueron atacadas, permitiendo la fuga de un gran número de prisioneros. Por otra parte, el aumento de ataques con VBIED era considerado una muestra del resurgimiento de ISI, dada la planificación y estructura logística requerida (Lewis, 2013, p. 8). Esta campaña es dividida por Jessica Lewis (2013), del Institute for the Study of War, en cuatro fases: 1) Prueba de la capacidad de ataque; esta incluyó el ataque a cuatro prisiones y su concentración en el norte de Irak. 2) Pausa y absorción, la cual presentó una disminución en las operaciones, mientras se absorbían en sus filas 
como parte de la yihad contra el enemigo chiita. Como señalaba el vocero de la organización

Tabla 3. Declaraciones de ISI entre 2011-2013

\begin{tabular}{|c|c|c|}
\hline TÍTULO & FECHA & DESGRIPGIÓN \\
\hline Iraq, Iraq, Oh Ahlu al-Sunnah & Enero 24, 2011 & $\begin{array}{l}\text { Declaración en la que se insta a la población sunnita a } \\
\text { reconocer el peligro proveniente de los chiitas. }\end{array}$ \\
\hline The Fighting Has Just Begun & Enero 25, 2011 & $\begin{array}{c}\text { Discurso en el que se declara la victoria frente a los } \\
\text { Estados Unidos y se solicita concentrar la lucha en } \\
\text { contra del gobierno iraquí. }\end{array}$ \\
\hline $\begin{array}{c}\text { I Only Advise You of One } \\
\text { [thing] }\end{array}$ & Mayo 21, 2012 & $\begin{array}{c}\text { Discurso donde se niegan las acusaciones hechas a } \\
\text { ISI de atacar musulmanes inocentes. Además, invita } \\
\text { a los sunnitas a arrepentirse por apoyar al enemigo } \\
\text { (en referencia al movimiento The awakening, que } \\
\text { consistió en un programa implementado por Estados } \\
\text { Unidos para utilizar a las tribus sunnitas en contra de } \\
\text { al-Qaeda en Irak). }\end{array}$ \\
\hline
\end{tabular}

Oh, the Fragrance of al-Jannah Junio 20, 2012

Discurso en el que se invita a la realización de la yihad y a unirse a los muyahidines en Diala, oriente de Irak.

Seven Facts Enero 31, $2013 \quad \begin{gathered}\text { Discurso que les recuerda a los sunnitas los agravios } \\ \text { y hechos que ha cometido el gobierno chiita en su } \\ \text { contra. Así, los invita a tomar las armas. }\end{gathered}$

Fight Them, for They are Polytheists
Junio 15, 2013 Texto que invita a la población sunnita a apoyar las
protestas en contra del gobierno y tomar las armas en
su contra a través del llamado a la yihad.

Fuente: elaboración propia. Esta ha sido elaborada según los discursos de Abu Mohammad al-Adnani, disponibles en https://khilafatimes.wordpress.com/ leadership/adnani/

\begin{abstract}
Abu Bakr al-Baghdadi declaró el comienzo de una nueva etapa de la acción yihadista para regresar a las regiones, controlarlas por la fuerza y derrotar al ejército de Safavidy sus partidarios. Él, que Allah lo proteja,
\end{abstract}

los prisioneros liberados; no obstante, la campaña se concentró en la frontera entre el Kurdistán e Irak, buscando explotar las tensiones kurdo-árabes. 3) La campaña de Bagdad, que coincidió con el inicio de las protestas en Irak y tuvo como objetivo la ciudad de Bagdad y sus alrededores; la comunidad chiita fue atacada con el fin de demostrar la incapacidad de las fuerzas de seguridad iraquíes. 4) Resurgir; esta última fase incrementó la presión sobre Bagdad y los chiitas, la cual concluyó con el ataque a la prisión de Abu Ghraib y la liberación de más de 500 prisioneros. 
declaró el plan de Demolición de los muros (Breaking the walls) y dio sus instrucciones y órdenes de atacar los ejes del proyecto Safavid y sus pilares, apuntar con precisión a los jefes del gobierno Safavid, a su cuartel general gubernamental, a sus centros militares y de seguridad, y a las guaridas malvadas de Rafidiy sus lacayos y matones traidores de sunitas. (al-Adnani, 2012, p. 4; traducción propia)

Estas campañas fueron filmadas y distribuidas a través de internet con el fin de intimidar y disuadir a las fuerzas de seguridad y a aquellos sunnitas que habían cooperado con el gobierno iraquí, grupos que eran considerados como audiencias. Así, se documentaron las conquistas de Faluya, Raqqa, Mosul, Samarra, Tikrit, entre otras ciudades. En especial, el video "Clanging of the Swords. Part IV" fue representativo.

En estos videos se mostraban ejecuciones, masivas o individuales, de miembros de las fuerzas armadas sirias e iraquíes con el fin de desmoralizarlas y amedrentarlas. Además, se caracterizaron -y en general la propaganda del Estado Islámico- por el constante uso de términos despectivos como rafida, safávida y nusayri con el fin de demostrar la intención de eliminar toda manifestación del chiismo y de otras religiones. Por ejemplo, en el video "Upon the Prophetic Methodology" (Estado Islámico, 2014b) se presentaba la masacre cometida en Camp Speicher, cerca de Tikrit, y la destrucción de diferentes santuarios chiitas en ciudades como Tal Alfar, Mosul, Tikrit y Samarra, haciendo uso de explosivos y buldóceres, para luego señalar la importancia de erradicar el chiismo como parte del cumplimiento y la defensa de la doctrina del tawhid.

En este sentido, el antichiismo es una parte esencial del discurso securitizador del Estado Islámico, bajo el cual presenta la amenaza que existe sobre la comunidad sunnita y el islam y justifica la necesidad de actuar contra el enemigo con total violencia para disuadirlo. Por ejemplo, el documento titulado "Ruling of Shari'a on the Shi'a Sects", publicado por la Oficina de Investigaciones y Estudios del Estado Islámico, señalaba a las diferentes sectas chiitas como apóstatas, e invitaba a que fueran atacadas por rechazar la religión, una ofensa mayor dentro del islam. También se hacía una conexión con el pasado al destacar la importancia estratégica de luchar primero contra el chiismo, en vez de los infieles (Occidente), como lo hizo Saladino, quien antes de tomar Jerusalén peleó contra el Imperio fatimí (al-Tamimi, 2017). 
El análisis de Fernandez (2015) de la propaganda del Estado Islámico entre 2006-2014, muestra cómo se adaptó a los nuevos contextos -por ejemplo, el inicio de la guerra en Siria-, con el fin de llegar y movilizar a una mayor audiencia, primero local y luego internacional. De este modo, los primeros videos estaban dirigidos a la población sunnita de Irak y presentaban los abusos norteamericanos en Abu Ghraib, el abandono del gobierno de al-Maliki y la alianza de este con Irán. Posteriormente, se utilizaron imágenes de los bombardeos de la coalición y del régimen sirio.

Esta narrativa de la victimización permitía justificar las acciones como las masacres, los atentados suicidas y las bombas en los mercados, pero también reclutar y tener mayor cantidad de simpatizantes. De esta manera, cuando comenzaron las protestas en la provincia de al-Anbar (Irak) y el conflicto en Siria se recrudeció (inicios de 2013), ISIS comenzó a publicar una gran cantidad de material acerca del conflicto sirio, mejoró la calidad de sus producciones y apeló a la yihad defensiva en busca de una audiencia más internacional. Así, comenzó la producción de material en inglés en el que destacaban las virtudes de los muyahidines y la importancia del martirio, acompanándolo con la presentación de versos del Corán (Lister, 2015, p. 171). Esta etapa de reclutamiento internacional se tradujo en el flujo de más de 11000 combatientes extranjeros provenientes de varios países de Medio Oriente y Europa (Lister, 2015, pp. 179-180).

Esta lucha sectaria se enmarcaba dentro de la batalla apocalíptica entre el bien y el mal. La visión de al-Zarqawi sobre Irak y el Levante como escenarios del enfrentamiento entre los infieles y los creyentes, permitió presentar los conflictos actuales como una de las señales del fin de los tiempos, por lo que es necesario para los creyentes estar del lado vencedor. El deseo de hacer parte de las grandes batallas del apocalipsis fue una de las motivaciones de los combatientes extranjeros, quienes se convirtieron en un factor destacado en la expansión del conflicto más allá de los escenarios locales.

De esta manera, el Estado Islámico integraba la situación de la comunidad sunnita en Irak y Siria, la doctrina salafista y las narraciones apocalípticas en su discurso securitizador. Esto le permitió alimentar las posturas anti-chiitas y el sentimiento de victimización de los sunnitas, con ello buscó mostrarse como único representante y defensor de esta comunidad, así como del islam más puro. 
Un último aspecto que integra tanto a las audiencias locales como a los simpatizantes internacionales fue la declaración del califato y la implementación de la Sharia. Estos representan la materialización de una utopía religiosa en la cual se encuentra segura la doctrina del tawhid y se vivencia la forma correcta de practicar la religión, pero también les permite tener control sobre la población que se encuentra bajo su poder.

En este sentido, la implementación de la Sharia, incluyendo los castigos huddud, mediante la institución de la hisba es un aspecto importante de la defensa del islam y del establecimiento de la legitimidad religiosa en la estrategia de gobernanza del Estado Islámico en los territorios que se encontraban bajo su dominio (Ospina Morales, 2019, p. 259). Regular y corregir los comportamientos de los musulmanes es un aspecto importante para enfrentar la amenaza de la idolatría, el politeísmo y la apostasía.

Por lo anterior, dentro de las estrategias de control territorial se realizaban quemas de cigarrillos y drogas, se prohibía la venta de alcohol, se controlaban los precios, se garantizaba el cumplimiento de la oración y se destruían los templos, tumbas y santuarios que promovían el politeísmo y la idolatría (Zelin, 2016, pp. 3-4). Sin embargo, este tipo de medidas generaron el rechazo de parte de la población, al señalar al Estado Islámico como un grupo brutal y violento. Es por esta razón que presentar la justificación teológica ante la población es necesario, como lo señaló alBaghdadi en el caso sirio.

Y para la gente de Siria: ustedes tienen a Dios, cualquiera negocia con tu sangre, compitiendo entre ellos de manera que podrían sentarse sobre tus hombros o, inclusive, sobre tu cadáver [...] pero tu sangre es nuestra sangre y tu destrucción es nuestra destrucción. Nosotros luchamos en el camino de Dios y para su satisfacción y no tenemos la culpa de los culpables. No se dejen engañar por los medios de comunicación porque nos encontrarán como los más amables con ustedes y los más duros con sus enemigos. Dios sabe que hicimos todo lo posible para defender a los musulmanes y luego de la noche a la mañana nos acusan de hacer takfir contra la población siria. Dios sabe que fuimos los únicos que luchamos contra los delincuentes y, de la noche a la mañana, ¿nos convertimos en asesinos y pusimos a nuestra gente en fosas comunes? Dios sabe que matones y ladrones huyeron de cada calle / área en la que entramos y, durante la noche, ¿se nos acusa de aterrorizar a la población local? Dios sabe que abrimos nuestros brazos hacia cada 
grupo y, luego, ¿se nos acusa de no reconocer a ningún muyahidín sino a nosotros mismos? Dios sabe que dejamos a nuestras familias y nuestros hogares para establecer la Sharia y, de la noche a la mañana, ¿se nos acusa de no volvernos hacia la Sharia? (al-Baghdadi, 2014, enero 19, p. 2; traducción propia)

Por otro lado, las acciones que implementó el Estado Islámico para eliminar la idolatría y el politeísmo representaron una amenaza existencial para las comunidades minoritarias. Tal fue el caso de los yazidíes, que fueron considerados como mushirk (politeístas) y, por esta razón, debían ser erradicados; sus mujeres podían ser esclavizadas y debían elegir entre la conversión o la muerte (Estado Islámico, 2014a, p. 15). También se consideraba importante la imposición del pacto dhimm ${ }^{26}$ sobre las comunidades cristianas, que implicaba la sumisión ante los musulmanes y el pago del impuesto de la jizyah. De esta manera, las acciones del Estado Islámico implementaron una campaña sistemática que buscaría eliminar la presencia de las minorías, ya que eran consideradas como representaciones del politeísmo y la idolatría (Ospina Morales, 2019).

\section{CONCLUSIÓN}

El caso del Estado Islámico en Irak y Siria representa una oportunidad para comprender las dinámicas de seguridad que se producen cuando la religión constituye un elemento central. Abordar este tipo de contextos permite reconocer nuevas posibilidades y límites conceptuales, lo que denomina Giovanni Sartori (1970, 1973 citado en Vuori, 2008) realizar un "viaje conceptual".

Aunque la Escuela de Copenhague ha utilizado el concepto de la securitización para analizar principalmente contextos democráticos en los que las medidas extraordinarias se consideran como acciones que no se permitirían en el escenario político habitual y que son reactivas frente a la amenaza, la securitización de la religión que conlleva el discurso salafistayihadista se presenta como una dinámica de doble vía, tanto ofensiva como defensiva, que busca asegurar la existencia del objeto referente. De este modo, las acciones del Estado Islámico buscan defender a la religión de los enemigos y todas las manifestaciones de aquello que contradiga y desvíe

26 Impuesto sobre la gente del libro (Ahl al-Kitâb o dhimmis) que viven bajo el dominio de los musulmanes. 
a los musulmanes de los principios y fundamentos del islam. Así mismo, se traduce en el ataque contra todo aquello que sea considerado como no islámico con el fin de eliminarlo, como fue el caso de las minorías de Irak y Siria.

Dados los límites que presenta la securitización frente a los elementos de la audiencia y el reconocimiento del "momento" en que se acepta el movimiento securitizador, explorar la relación entre la audiencia y el actor securitizador aún se concentra en la importancia del acto discursivo. Es por esta razón que propuestas como las "ramas de la securitización" permiten comprender los diferentes fines e intenciones por las que se convierte un asunto en un tema de seguridad. De esta manera, la propaganda del Estado Islámico presenta un discurso securitizador que, como grupo salafista, se concentra en la defensa del principio del tawhid, que le permite articular sus acciones frente a los enemigos-que define en términos teológicos-, establecer sus objetivos, justificar sus acciones y legitimar su control sobre la población.

En este sentido, la propaganda tuvo un papel fundamental en la transmisión del discurso salafista-yihadista a audiencias tanto locales como internacionales en busca de seguidores y simpatizantes, gracias a los aspectos teológicos y de victimización del mensaje. Por su parte, la violencia sirvió para amedrentar a las fuerzas de seguridad y a sus enemigos. De tal modo, el Estado Islámico se convirtió en el grupo salafista-yihadista más importante de la actualidad y una de las principales amenazas a la seguridad internacional.

\section{REFERENCIAS}

al-Adnani, A. M. (2011, agosto 7). The State of Islam will Remain Safe. https://pdfs. semanticscholar.org/a313/da7f40150e6fc0c16af42773ac42c51b5b3b.pdf?_ ga $=2.25450045 .1236202398 .1588504707-662697385.1588504707$

al-Adnani, A. M. (2012, noviembre 1). Stormings Are More Painful. Al-Furqan Media. https://www.yumpu.com/en/document/read/28360969/shaykh-abc5abmue1b8a5ammad-al-adnc481nc4ab-22the-incursions-are-deadlier22-en al-Adnani, A. M. (2014, junio 29). This is the Promise of Allah. https://www.yumpu. com/en/document/read/52152130/shaykh-abc5ab-muelb8a5ammad-ale28098adnc481nc4ab-al-shc481mc4ab-22this-is-the-promise-of-god22-en

al-Baghdadi, A. B. (2014, enero 19). Translation of the new audio-message by Abü Bakr al-Baghdā $d \bar{\imath}$. Al-Hayat Media Center. https://scholarship.tricolib.brynmawr. edu/bitstream/handle/10066/16409/ABB20140119.pdf 
al-Baghdadi, A. B. (2014, julio 1). Message To the Mujāhidīn and the Islamic Ummah In the Month Of Ramadān. Al-Hayat Media Center. https://jihadology. net/2014/07/01/al-furqan-media-presents-a-new-audio-message-from-theislamic-states-abu-bakr-al-\%e1\%b8\%a5ussayni-al-qurayshi-al-baghdadimessage-to-the-mujahidin-and-the-islamic-ummah-in-the-month-of-rama/ al-Tamimi, A. J. (2017, julio 18). Islamic State Treatise: Ruling of Shari'a on the Shi'a Sects [Entrada de blog]. http://www.aymennjawad.org/20083/islamic-statetreatise-ruling-of-Sharia-on

al-Zarqawi, A. M. (2004, febrero). Zarqawi Letter [English translation of terrorist Musab al Zarqawi letter obtained by United States Government in Iraq. U.S. Department of State]. https://2001-2009.state.gov/p/nea/rls/31694.htm\#

Ayoob, M. (2004). Political Islam: Image and Reality. World Policy Journal, 21(3), 1-14. https://doi.org/10.1215/07402775-2004-4011

Balzacq, T., Léonard, S. y Ruzicka, J. (2015). "Securitization" revisited: Theory and cases. International Relations, 30(4), 484-531. https://doi. org $/ 10.1177 / 0047117815596590$

Buzan, B. (2007). People, States and Fear: an agenda for the international security studies in the post-cold war era. ECPR press.

Buzan, B. y Hansen, L. (2010). The Evolution of International Security Studies. Cambridge University Press. https://doi.org/10.1177/0967010610388214

Buzan, B., Waever, O. y Wilde, J. de. (1998). Security: A Framework for the Analysis. Lynne Reinner Publishers.

Esposito, J. L. (Ed.). (2003). Oxford Dictionary of Islam. Oxford University Press. http://www.oxfordislamicstudies.com/browse?type=article

Estado Islámico. (2014a). The revival of slavery before the hour. Dabiq, 4, 14-18. https://www.ieproject.org/projects/dabiq4.pdf

Estado Islámico. (2014b, julio 28). Upon the Prophetic Methodology. Al-Furqān Media. https://jihadology.net/2014/07/28/al-furqan-media-presents-a-new-videomessage-from-the-islamic-state-upon-the-prophetic-methodology/

Fernandez, A. M. (2015). Here to Stay and Growing: Combating ISIS propaganda network. The Brookings Project on U.S. Relations with the Islamic World. Center for the Middle East Policy at The Brookings Institution. https://www.brookings. edu/wp-content/uploads/2016/06/IS-Propaganda_Web_English.pdf

Gartenstein-Ross, D., Fritz, J., Moreng, B. y Barr, N. (2015). Islamic State Vs AlQaeda. Strategic Dimensions of a Patricidal Conflict. New America. International Security Program. https://static.newamerica.org/attachments/12103-islamicstate-vs-al-qaeda/ISISvAQ_Final.e68fdd22a90e49c4af1d4cd0dc9e3651.pdf

Human Rights Watch. (2013). "No One Left". Summary Executions by Syrian Forces in al-Bayda and Baniyas. https://www.hrw.org/report/2013/09/13/no-ones-left/ summary-executions-syrian-forces-al-bayda-and-baniyas

Izquierdo Brichs, F. (Ed.). (2013). El islam político en el Mediterráneo. CIDOB, Centro de Información y Documentación de Barcelona.

Kfir, I. (2015). Social Identity Group and Human (In)Security: The Case of Islamic State in Iraq and the Levant (ISIL). Studies in Conflict y Terrorism, 38(4), 233252. https://doi.org/10.1080/1057610X.2014.997510 
Landis, J. (2013, diciembre 15). Zahran Alloush: His Ideology and Beliefs [Entrada de blog]. Syria Comment. Syrian Politics, History, and Religion. http://www. joshualandis.com/blog/zahran-alloush/

Laustsen, C. B. y Waever, O. (2003). In Defense of Religion. Sacred referent objects for securitization. En F. Petito y P. Hatzopoulos (Eds.), Religion in International Relations. The return de exile (pp. 147-180). Palgrave Macmillan. https://doi.org/10.1057/9781403982360_6

Lewis, J. D. (2013). Al-Qaeda in Iraq Resurgent. The breaking the walls campaing, Part $I$ [Middle East Security Report $\left.\mathrm{N}^{\circ} 14\right]$ ]. Institute for the Study of War. http:// www.understandingwar.org/sites/default/files/AQI-Resurgent-10Sept_0.pdf

Lister, C. R. (2015). The Syrian Jihad. Oxford University Press.

Maher, S. (2017). Salafi-Jihadism: the history of an idea. Penguin Books.

Martin, C. y Barzegar, A. (Eds.). (2010). Islamism: Contested Perspectives on Political Islam. Stanford University Press. https://doi.org/10.1515/9780804773355

McCants, W. (2015). The ISIS Apocalypse. The History, Strategy, and Doomsday Vision of the Islamic State. Saint Martin's Press.

McDonald, M. (2008). Securitization and the Construction of Security. European Journal of International Relations, 14(4), 563-587. https://doi. org/10.1177/1354066108097553

McSweeney, B. (1996). Identity and Security: Buzan and the Copenhagen School. Review of International Studies, 22(1), 81-93. https://doi.org/10.1017/ S0260210500118467

Meijer, R. (2010). Salafism: Doctrine, Diversity and Practice. En K. Hroud (Ed.), Political Islam. Context versus Ideology (pp. 37-60). SAQI; London Middle East Intitute SOAS.

Ospina Morales, G. (2019). Religión e identidad. La amenaza del Estado Islámico en Irak y Siria. Desafios, 31(1), 193-235. https://doi.org/10.12804/revistas. urosario.edu.co/desafios/a.6206

Saeed, H. (2015). The Islamic State in Iraq and Al-Sham in Iraq: Integrating the Sunni Policy in the Salafist Ideology. En Friedrich Ebert Stiftung, The Rise of Religious Radicalism in the Arab World: Significance, Implications and CounterStrategies (pp. 67-85). FES Jordan e Iraq. http://library.fes.de/pdf-files/ bueros/amman/11463.pdf

Saleh, A. (2010). Broadening the Concept of Security: Identity and Societal Security. Geopolitics Quaterly, 6(4), 228-241.

Sheikh, M. K. (2014a). Doctrinal War. E-International Relations. http://www.e-ir. info/2014/01/15/doctrinal-war/

Sheikh, M. K. (2014b). The Religious Challenge to Securitisation Theory. Millenium: Journal of International Studies, 43(1), 252-272. https://doi. org $/ 10.1177 / 0305829814540853$

Stern, J. y Berger, J. (2015). ISIS, The State of Terror. William Collins.

Veiga, F. (2009). El Desequilibrio como Orden: Una historia de la posguerra fría 19902008. Alianza Editores. 
Vuori, J. (2008). Illocutionary Logic and Strands of Securitization: Applying the Theory of Securitization to the Study of Non-Democratic Political Orders. European Journal of International Relations, 14(1), 65-99. https://doi. org/10.1177/1354066107087767

Wagemakers, J. (2017). Revisiting Wiktorowicz. Categorising and Defining the Branches of Salafism. En F. Cavatorta y F. Merone (Eds.), Salafism After the Arab Awakening: Contending with People's Power (pp. 7-24). Oxford Scholarship Online. https://doi.org/10.1093/acprof:oso/9780190274993.003.0002

Weiss, M. y Hassan, H. (2015). ISIS, Inside the Army of Terror. Regan Arts.

Wiktorowicz, Q. (2006). Anatomy of the Salafi Movement. Studies in Conflict $\mathcal{E}$ Terrorism, 29(3), 207-239. https://doi.org/10.1080/10576100500497004

Zelin, A. Y. (2016). The Islamic State's Territorial Methodology. Research Notes 29, The Washington Institute for Near East Policy. http://www.washingtoninstitute. org/policy-analysis/view/the-islamic-states-territorial-methodology 